\title{
Rod End Stress Analysis for Hydraulic Cylinder of Live Floor Conveying System
}

\author{
Evaldas NARVYDAS*, Romualdas DUNDULIS**, Nomeda PUODZIUNIENE*** \\ *Kaunas University of Technology, Studentu st. 56, LT-51424 Kaunas, Lithuania, E-mail: evaldas.narvydas@ktu.lt \\ **Kaunas University of Technology Studentu st. 56, LT-51424 Kaunas, Lithuania, E-mail: romualdas.dundulis@ktu.lt \\ ***Kaunas University of Technology Studentu st. 56, LT-51424 Kaunas, Lithuania, E-mail: nomeda.puodziuniene@ktu.lt \\ cross'ref http://dx.doi.org/10.5755/j01.mech.26.2.24675
}

\section{Introduction}

Rod ends of hydraulic cylinders have a long history of operation in various engineering installations. However, cases of unexpected failures still can be found in industry reports and articles [1,2], because of design, material and/or operational flaws. This article deals with stress analysis of the rod end where company producing hydraulic cylinders for live floor installations reported several failures of the rod eye. The stress analysis gives an important understanding if the design of the component is correct regarding the operational conditions and used material. A typical reported failure is shown in Fig. 1. The outer ring of the rod eye was broken at the location of the weld toe. The stress analysis techniques of the welded structures are presented in a large number of research articles. General overviewed was performed by Fuštar et al. in [3] and by den Besten with emphasis on marine structures [4]. Recommendations for design against fatigue of welded structures are summarized by Hobbacher [5]. Modern approach of stress analysis of welded structures and modeling employing special shell type finite element models can be found in [6]. Practical aspects and benchmark studies with ANSYS software are presented in [7].
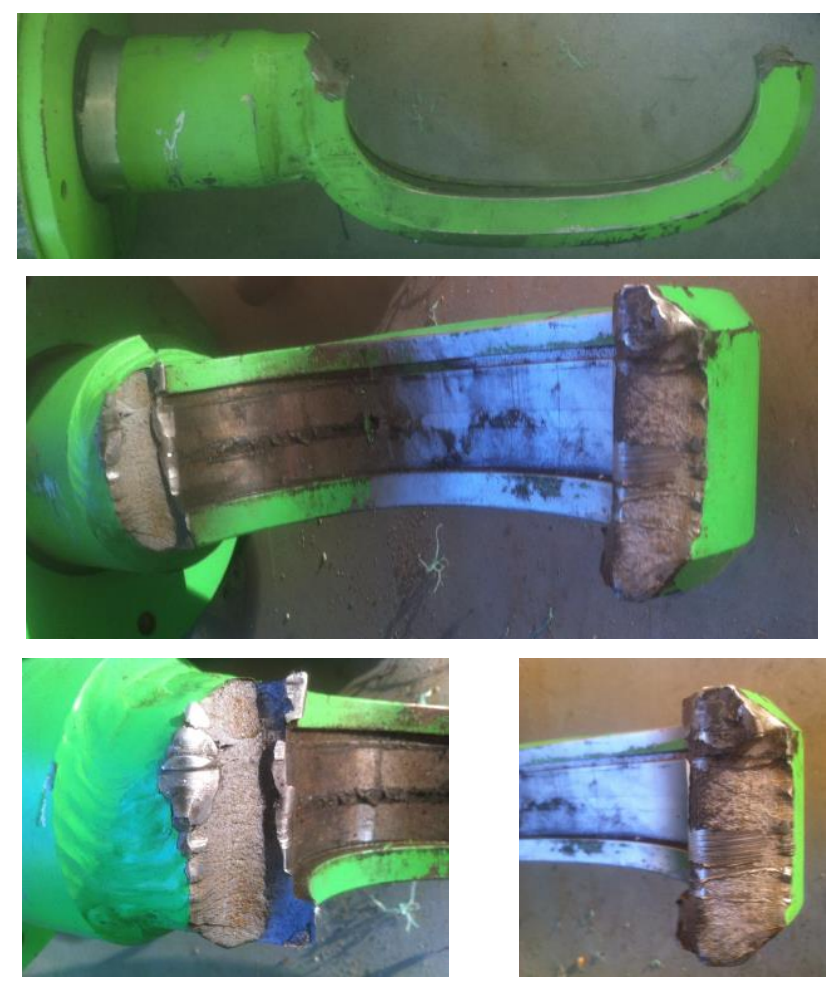

Fig. 1 Photos of the broken eye of the hydraulic cylinder rod

\section{Design of the rod eye}

\subsection{Geometry of the rod eye and weld}

The failed rod eye contains an outer ring, bushing and an inner ring (Fig. 2). The pin (not shown in the Fig. 2) is inserted in to the inner ring for the load transfer. The outer ring is welded to the rod end of the hydraulic cylinder. The bushing and the inner ring are joined by a spherical interface. This allows side rotations of the inner ring up to $15^{\circ}$. The similar eye is welded to the cover of the hydraulic cylinder at the opposite end. This design ensures that the cylinder and the rod are subjected only to the axial forces when loaded.
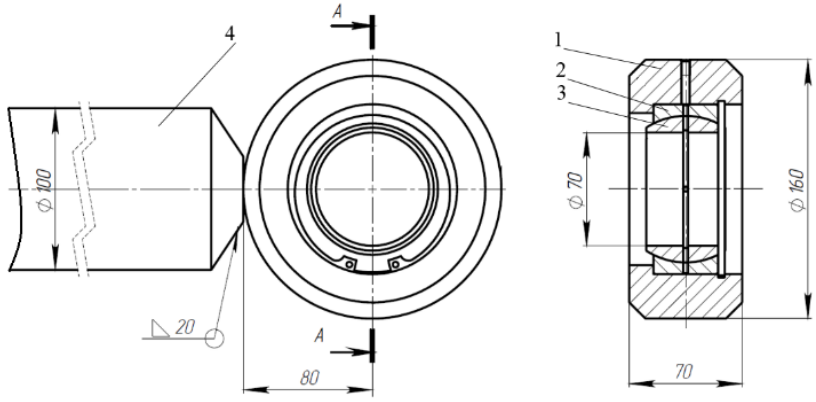

Fig. 2 Design of the failed rod eye of the hydraulic cylinder: outer ring 1 , bushing 2 , inner ring $3, \operatorname{rod} 4$
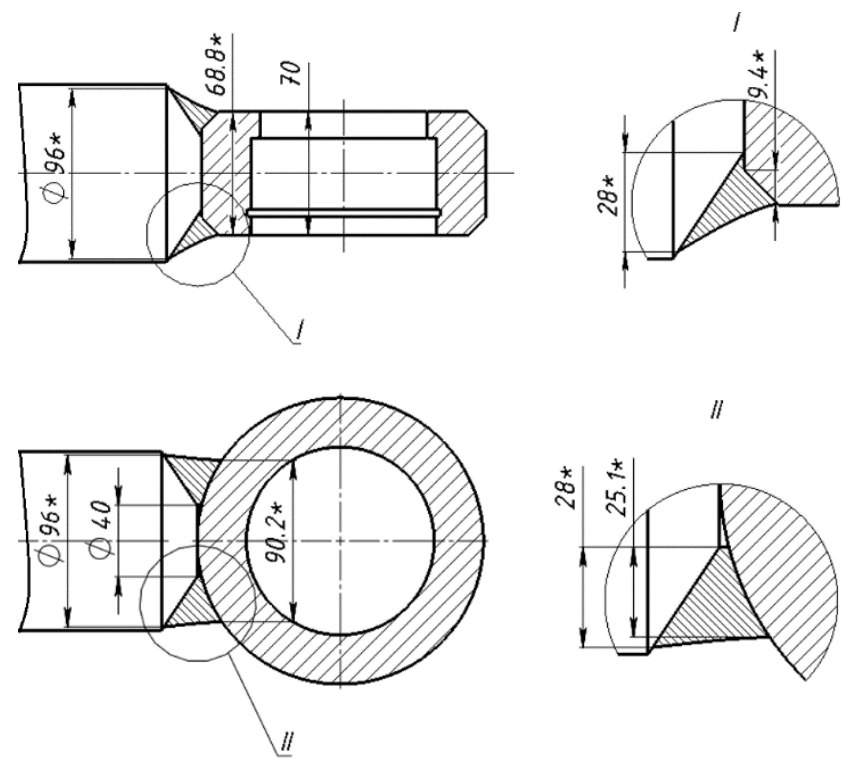

Fig. 3 Geometry of the weld

The primary aim of the research was to examine 
the stresses at the place of failure, therefore only the outer ring, weld and rod were considered for the stress analysis. Geometry of the weld (Fig. 3) was constructed according to design drawings and figures of the actual rod-eye joint (Fig. 1).

\subsection{Material properties of the rod eye assembly}

Three diferrent materials were used in the rod eye assembly: material of the rod - steel C45E EN 10083-2, material of the eye - steel S355J2G3 EN 10025-2 and material of the weld G3Si1 EN ISO 14341-A. Mechanical properties of these materials acording to inspection certificates are presented in Table 1. Young's modulus and Poisson's ratio for all materials was assumed $200000 \mathrm{MPa}$ and 0.3 .

Table 1

Mechanical properties

\begin{tabular}{|c|c|c|c|c|}
\hline Component & Steel grade & $R_{p 0.2}, \mathrm{MPa}$ & $R_{m}, \mathrm{MPa}$ & $A_{5}, \%$ \\
\hline Rod & C45E & 369 & 652 & 24 \\
\hline Eye & S355 J2G3 & 326 & 506 & 30 \\
\hline Weld & G3Si1 & 470 & 560 & 26 \\
\hline
\end{tabular}

For nonlinear stress analysis the stress strain relation of the materials uniaxial tension diagram was aproximated by bilinear curves where the elastic-plastic relation is presented by tangent modulus $E_{T}$ (Fig. 4). For the $\mathrm{C} 45 \mathrm{E}$ the $E_{T}=1172 \mathrm{MPa}$, for S355J2G3 $E_{T}=600 \mathrm{MPa}$ and for weld material $E_{T}=346 \mathrm{MPa}$.

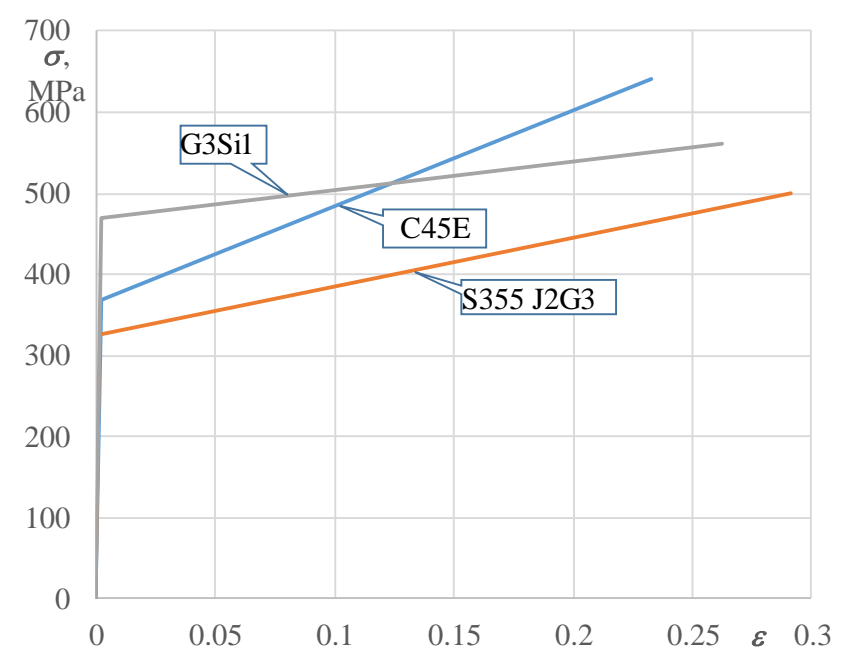

Fig. 4 Bilinear stress-strain relations of the rod end materials

\section{Finite element model for the stress analysis}

In the presented case, the 3D solid finite element mesh was usesd to find the stresses at the failed crosssection of the rod eye including the stress concentration zone at the weld toe (Fig. 5, ANSYS SOLID186 finite element type). A 3D geometry of the rod eye assembly was created with SOLIDWORKS software, and then transferred to the ANSYS for the finite element analysis (FEA). The left end of the rod was fixed. The load was applied on the specially created pin inside the eye ring (Fig. 6). The main direction of the loading force was horizontal $(x)$; however, some variation of it was examined in a range from $0^{\circ}$ to $20^{\circ}$ in $x$ - $y$ plane. There are different ways how the loading of the rod eye can be simulated depending on the fitting of the inner elements of the rod eye assembly. Here the load was transferred to the rod eye by a pin that perfectly fits the eye and established a frictional contact between the loaded pin and the eye ring with assumed friction coefficient 0.2.

The calculations were performed applying $20 \mathrm{MPa}$ pressure inside the cylinder. Having inside diameter of the cylinder $200 \mathrm{~mm}$ and diameter of the rod $100 \mathrm{~mm}$, the force on the pin during extention of the rod was $628.3 \mathrm{kN}$ and the retraction force was $471.2 \mathrm{kN}$.

Geometry of the assembly had a few variations. According to common practices of the effective notch stress approach of the fatigue assessment of welded structures [3, 4] the artificial $1 \mathrm{~mm}$ notch (fillet) radius at the weld toe was used. The model with a notch (Fig. 7) was tested; the model without a notch was also used for comparison. The influence of the penetration of but weld and formation of non-welded gap at the root was tested as well. The $3 \mathrm{D}$ geometry model transferred for FEA had no symmetry simplifications, because the eye ring is not symmetric in respect to frontal ( $x$ $y$ ) plane and loading force had variations of direction angle regarding horizontal $(x-z)$ plane.

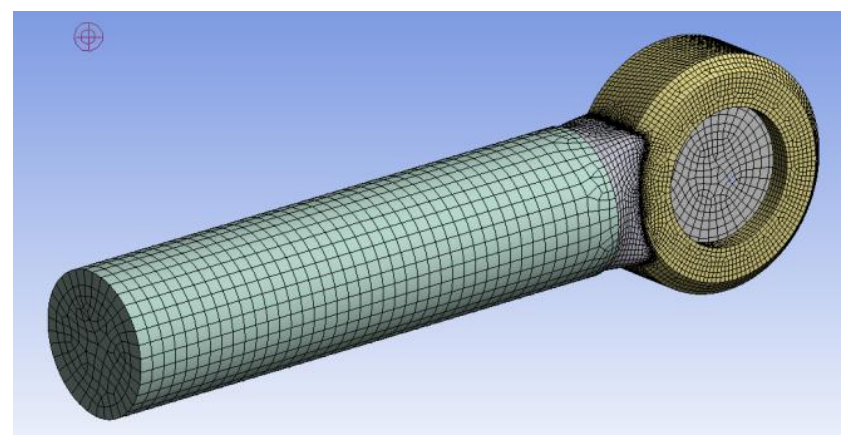

Fig. 5 Example of the assembly mesh

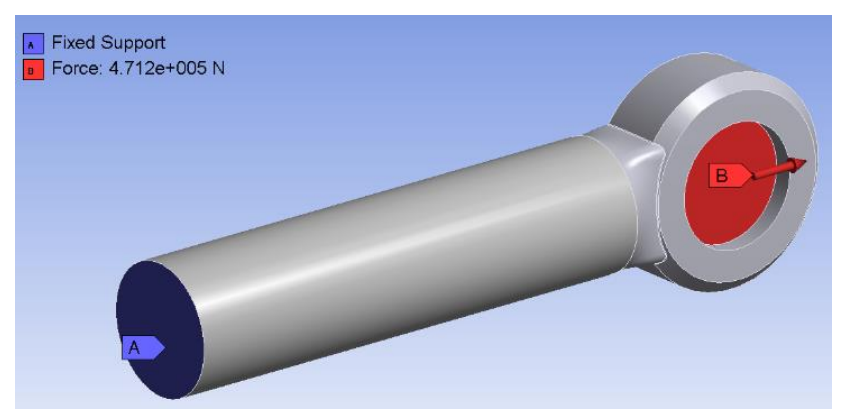

Fig. 6 3D geometry model of the assembly with boundary conditions for the FEA

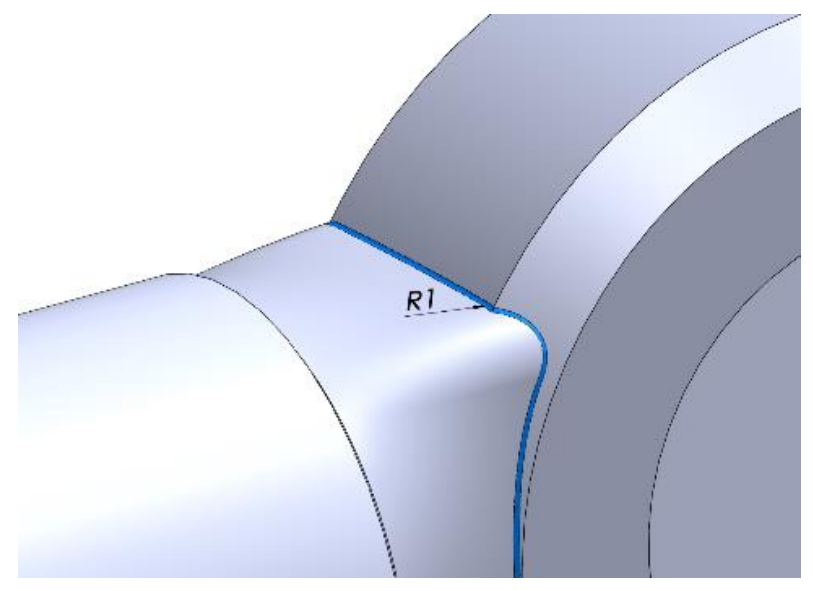

Fig. $71 \mathrm{~mm}$ notch at the weld toe 


\section{Results and discussion}

Von Mises stress calculated when the rod retraction force was pulling the eye is presented in Fig. 8. The pin with the applied load is hidden for clarity. The linear elastic stress has a very sharp stress concentration at the eye weld toe (Fig. 8,a). The application of the artificial $1 \mathrm{~mm}$ radius reduces the maximal stress (Fig. 8, $b$ ), but it still is 3.8 times the yield limit of the eye material. Only elastic-plastic analysis reduces the maximum of stresses to 1.6 (Fig. 8, c) and 1.06 (Fig. 8, d) of the yield limit. The stress values on the midline of the failed cross-section (Fig. 9) were extracted for more convenient comparison of the stress results (Fig. 10). The midline is presented by path from 1 to 2 in the Fig. 10. The penetration of but weld and formation of nonwelded gap at the root with $40 \mathrm{~mm}$ gap and $20 \mathrm{~mm}$ gap showed a negligible influence to the stress results on the cross-section of interest.

The maximum principle (normal) stresses were also checked for comparison. These stresses may also be used for the fatigue and failure evaluation of the welded structures [7]. For the failed cross-section, it would be the hoop stresses of the rod eye. These stresses are shown in Figs. 11, 12 and 13 with the reference to created cylindrical coordinate system having the origin in the eye center.

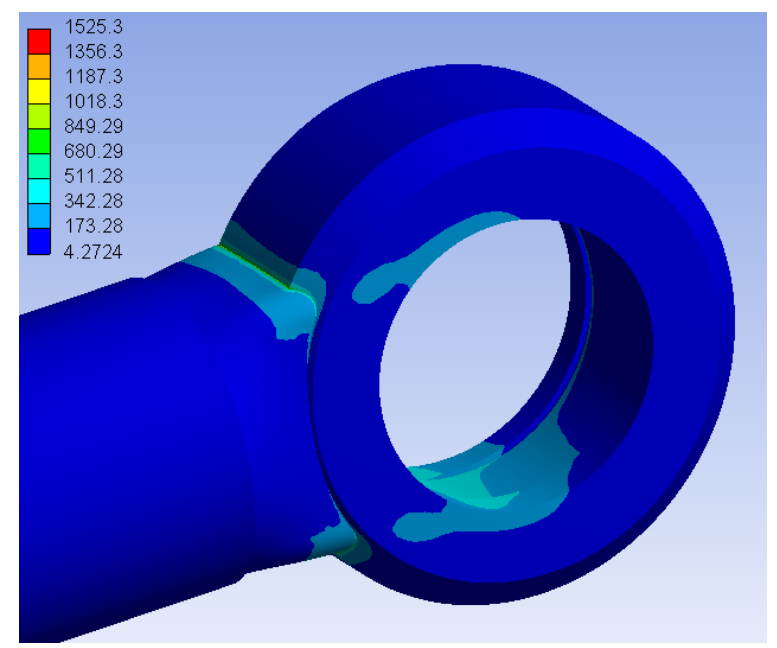

a

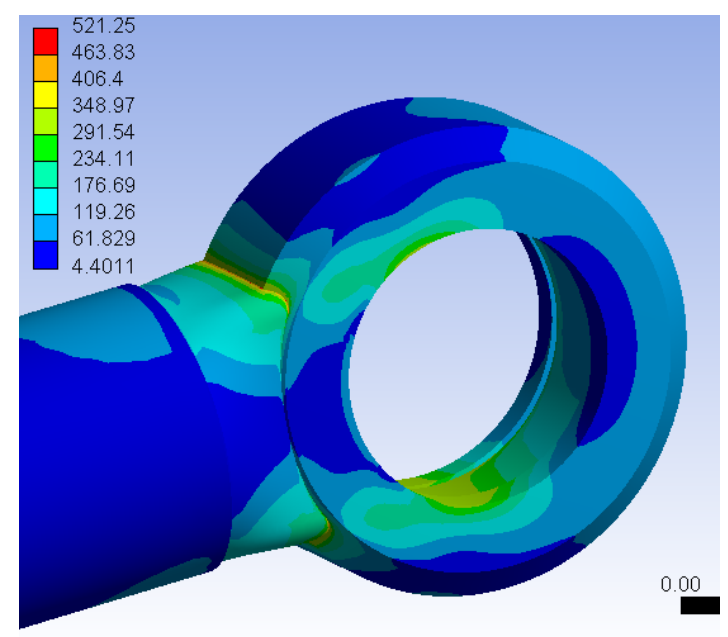

$\mathrm{c}$
It was noticed, from the stress curves in Figs. 10 and 13 that the stress values become close to each other at the location of $1 \mathrm{~mm}$ radial distance from the weld toe (at radius point $79 \mathrm{~mm}$ from the eye center). The stress values calculated for variants with the $1 \mathrm{~mm}$ fillet and without fillet, also employing elastic and elastic-plastic behavior of material are presented in (Table 2). Comparing cases with fillet and without fillet, the von Mises stress for the elastic solution differ $1 \%$ and $2.2 \%$ for the elastic-plastic solution; the hoop stress differences are $6 \%$ for elastic solution and $0.7 \%$ for the elastic-plastic one. These results draw a conclusion that the stresses at $1 \mathrm{~mm}$ distance from the weld toe are more reliable for the strength and fatigue evaluation, than the effective stress at the root of $1 \mathrm{~mm}$ fillet.

Table 2

Stresses at $1 \mathrm{~mm}$ distance from the weld toe

\begin{tabular}{|l|l|l|l|}
\hline \multicolumn{3}{|c|}{ Von Mises stress, MPa } & Hoop stress, MPa \\
\hline Fillet R0 & Fillet R1 & Fillet R0 & Fillet R1 \\
\hline \multicolumn{4}{|c|}{ Elastic solution } \\
\hline 312 & 309 & 331 & 351 \\
\hline \multicolumn{4}{|c|}{ Elastic-plastic solution } \\
\hline 318 & 325 & 413 & 410 \\
\hline
\end{tabular}

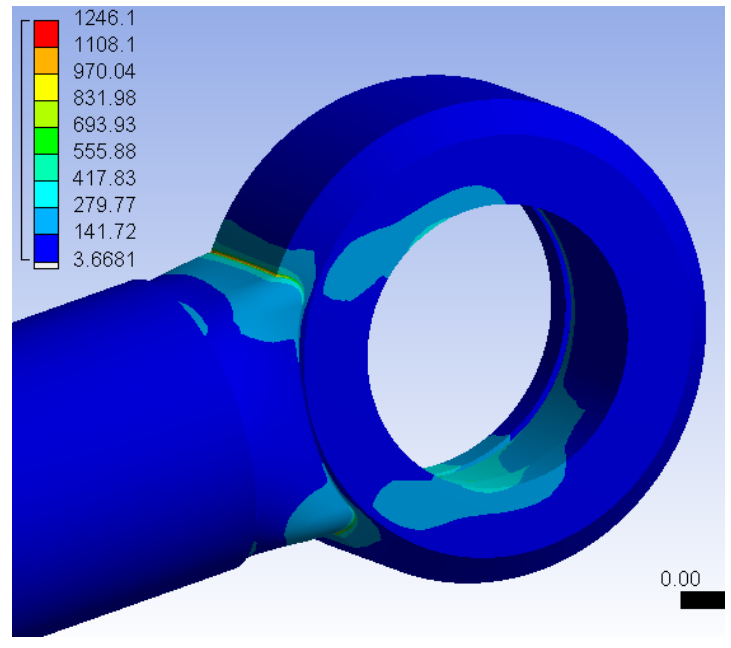

b

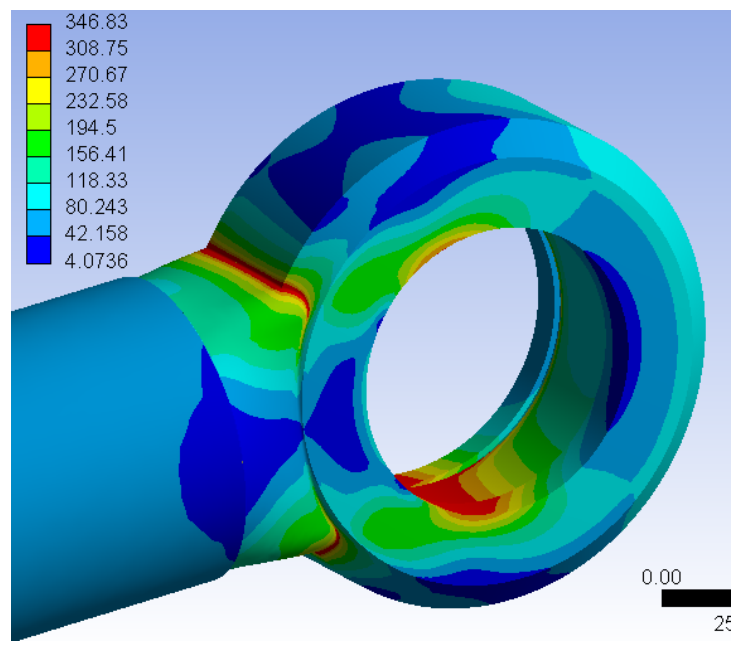

d

Fig. 8 Equivalent von Mises stress in the eye model: a) elastic stress without a fillet at the weld toe, b) elastic stress with 1 $\mathrm{mm}$ fillet at the weld toe, c) elastic-plastic stress without fillet at the weld toe, d) elastic-plastic stress with $1 \mathrm{~mm}$ fillet at the weld toe 


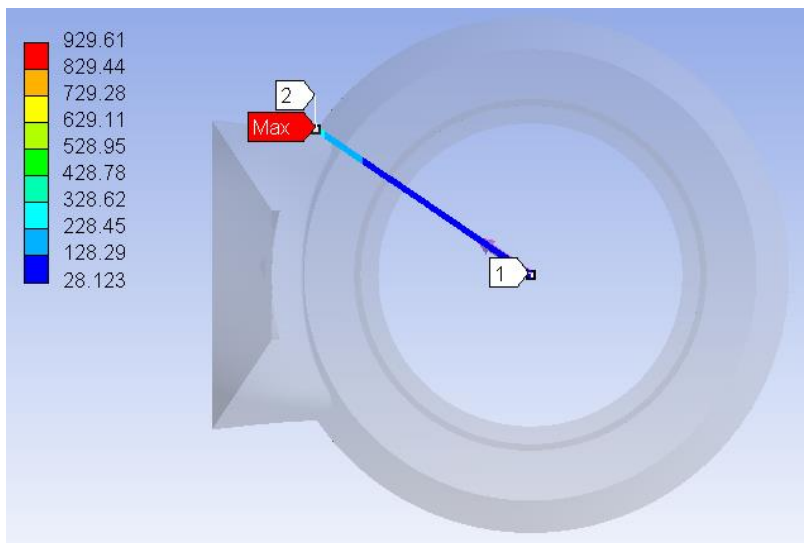

Fig. 9 Von Mises stress extraction on the mid line of the failed cross-section
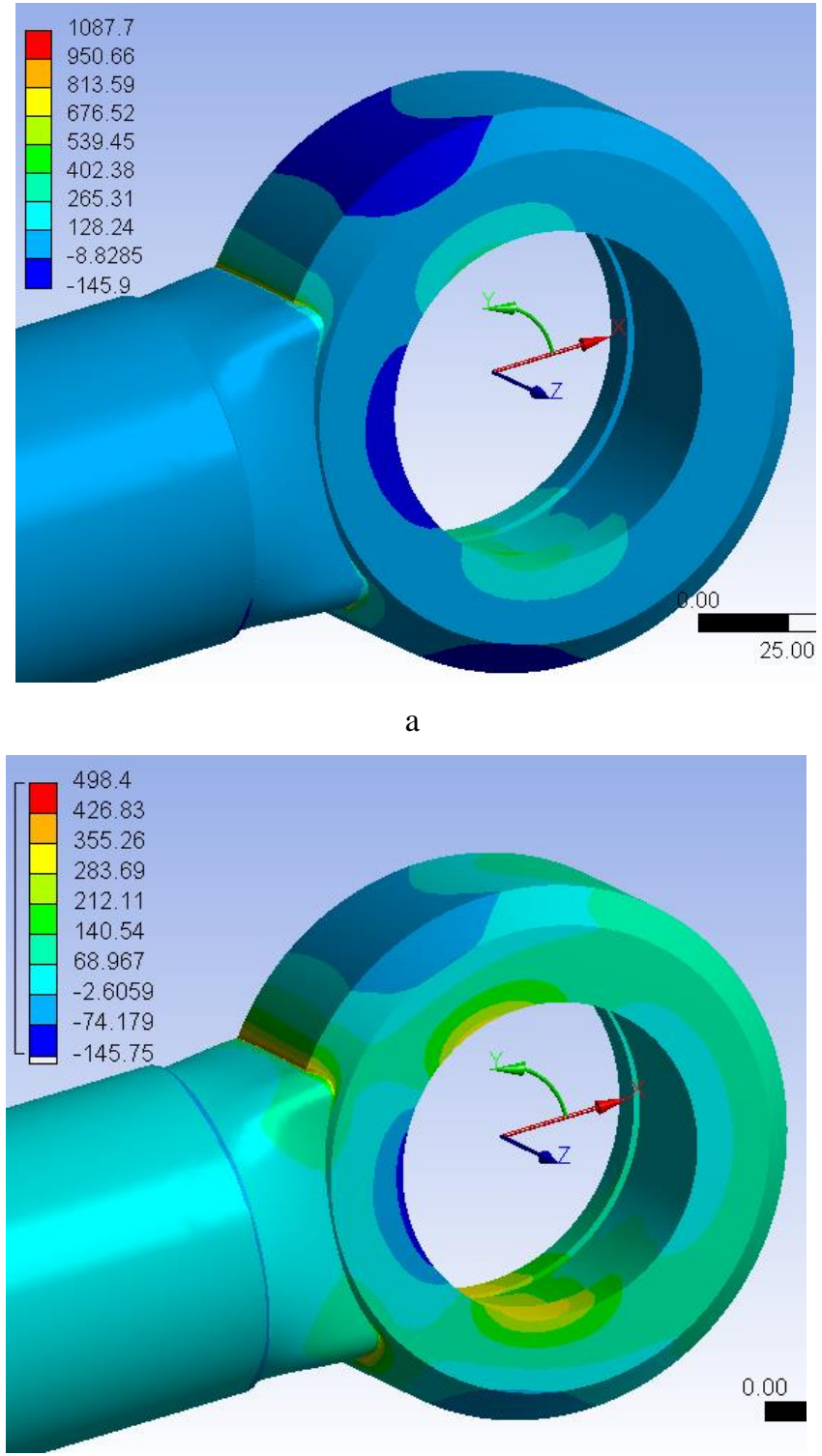

a

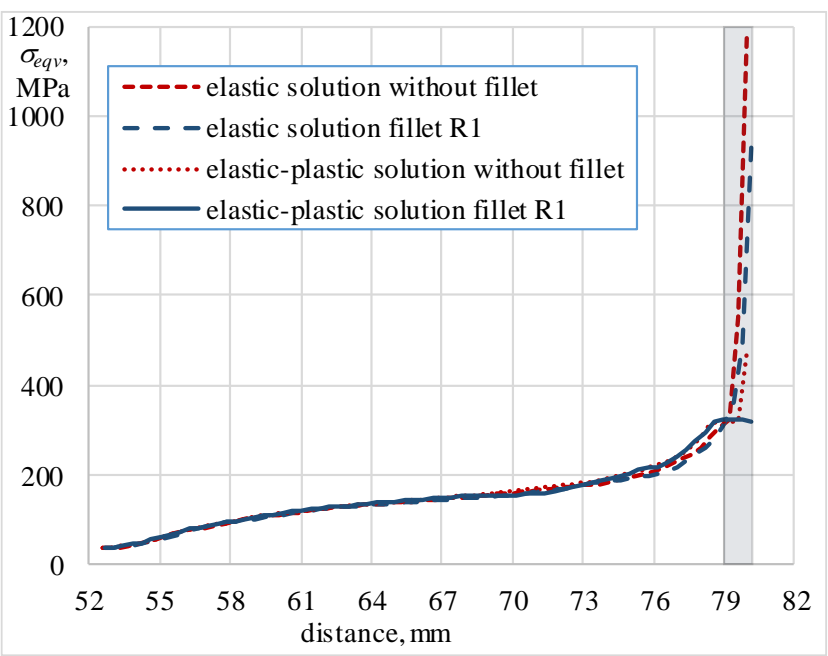

Fig. 10 Von Mises stresses on the midline of the failed cross-section: result comparison

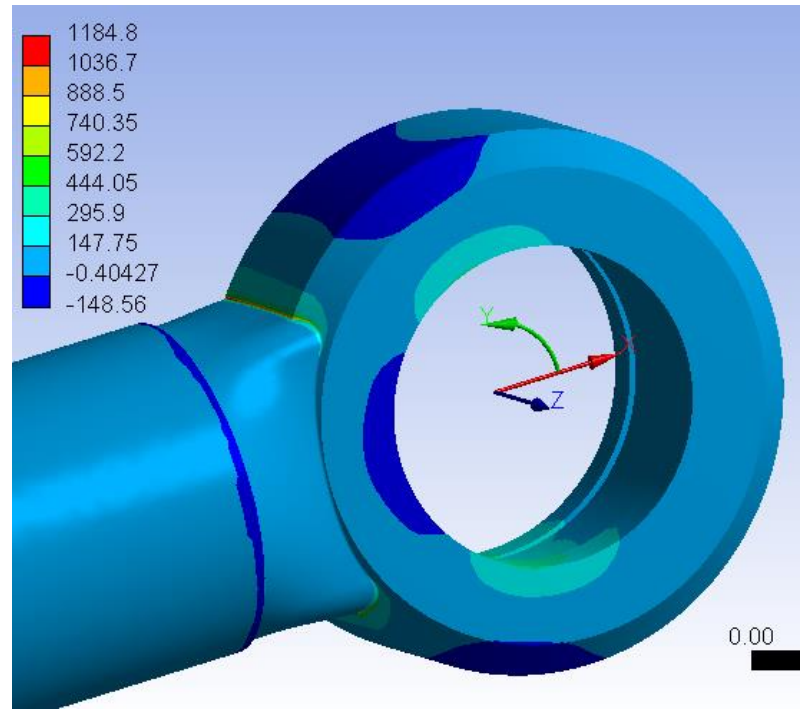

b

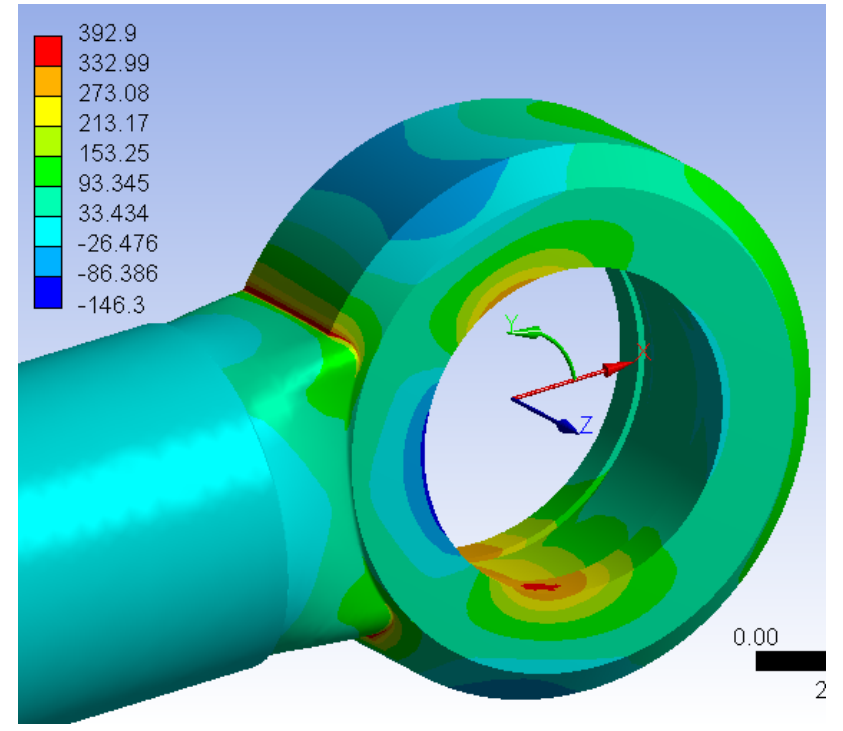

b

Fig. 11 Hoop stress in the eye model: a) elastic stress without fillet at the weld toe, b) elastic stress with $1 \mathrm{~mm}$ fillet at the weld toe, c) elastic-plastic stress without fillet at the weld toe, d) elastic-plastic stress with $1 \mathrm{~mm}$ fillet at the weld toe 


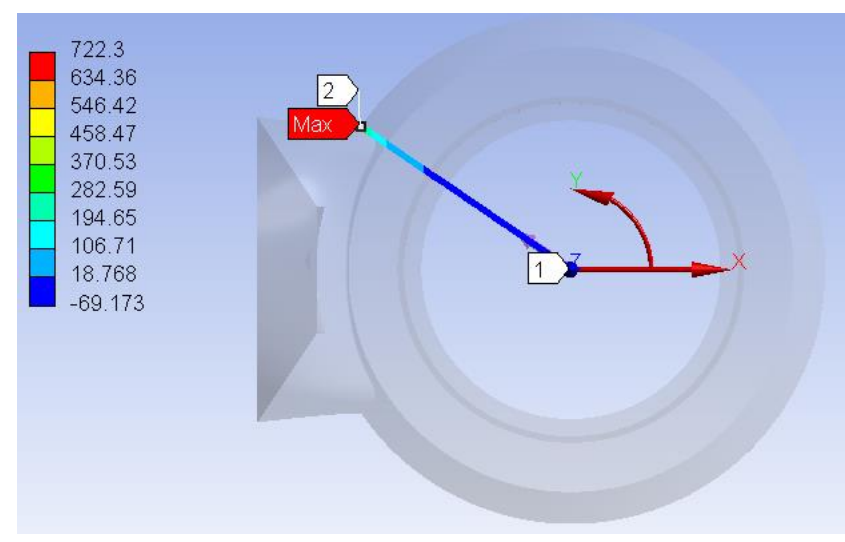

Fig. 12 Hoop stress extraction on the mid line of the failed cross-section in cylindrical coordinate system

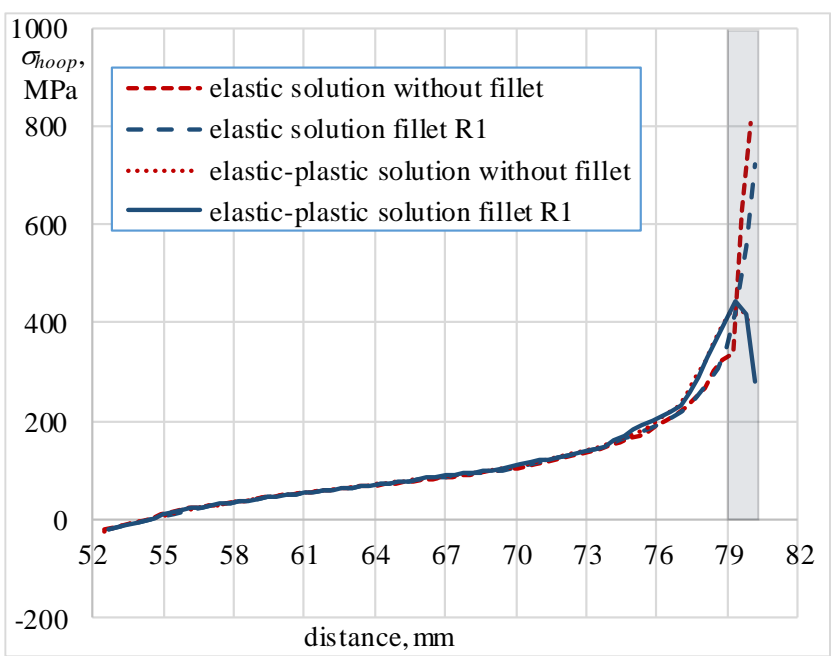

Fig. 13 Hoop stresses on the midline of the failed cross-section: result comparison

The other concern of this research was an assumption that the inappropriate mounting and operation of the cylinder could damage the rod eye during the rod extension. It was assumed that the rotation of the cylinder was restricted and the rod was misaligned by an angle $\alpha$ to the external load and the resultant reaction in the rod eye. Influence of misalignment and geometric weld imperfections for the fatigue assessment of welded joints was studied in [8]. However, the presented article assumes the global misalignment of the structure. The resultant reaction then would be expressed as: $R_{\text {sum }}=R_{x} / \cos \alpha$, where $R_{x}=-628.3 \mathrm{kN}$ under the operational pressure $p=20 \mathrm{MPa}$. The schematic diagram of the cylinder mounting and the reaction forces on the rod eye is shown in Fig. 14. Von Mises stress was calculated under the misalignment of $\alpha=15^{\circ}$ and $20^{\circ}$ (Fig. 15). This loading case show the increase of stresses in the cross-section at the location of failure. Therefore, assumed conditions of operation of the hydraulic cylinder would significantly increase a possibility of damage of the rod eye.

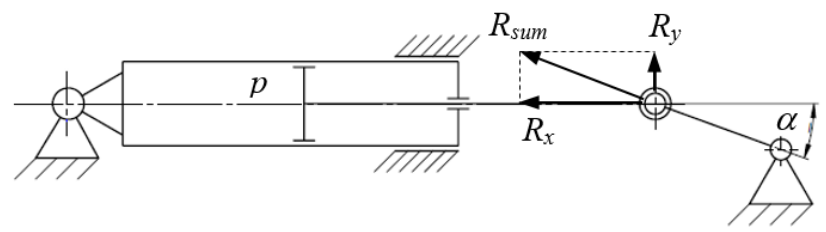

Fig. 14 Schematic diagram of an assumed mounting of the hydraulic cylinder and misalignment of the reaction

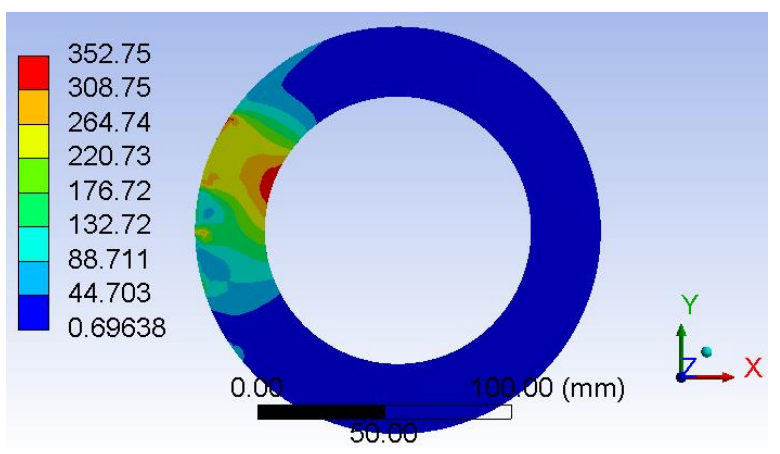

a

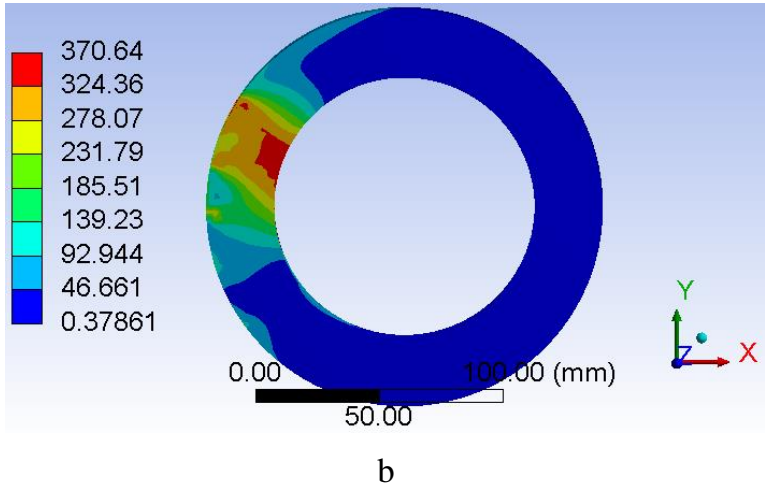

Fig. 15 a)Von Mises stress under the misalignment of $15^{\circ}$ and b) $20^{\circ}$

\section{Conclusions}

The stress analysis of the eye welded to the rod of the hydraulic cylinder was performed employing finite element method. The variants of analysis consisted of: the eyeweld connection with $1 \mathrm{~mm}$ artificial notch and without the notch, elastic and elastic-plastic behavior of the materials, load case puling the eye and compressing the eye under the misalignment of the rod. The analysis results allow to conclude:

1) the $1 \mathrm{~mm}$ notch reduces the stress maximum, but still creates a sharp stress concentration for the presented case under the linear elastic deformation, assuming von Mises stress as the equivalent at the $1 \mathrm{~mm}$ distance from the weld toe would give results close to the non-linear solution within range of $5 \%$ difference;

2) fixed rotations of the cylinder and misaligned load would cause increase of stresses at the location of the observed failed cross-section of the eye under the compression load.

\section{Acknowledgement}

The authors would like to acknowledge Mr. Algirdas Vigelis for providing photos of the failed rod eye case.

\section{References}

1. Asi, O.; Yeşil., Ö. 2013. Failure analysis of an aircraft nose landing gear piston rod end, Engineering Failure Analysis 32: 283-291. http://dx.doi.org/10.1016/j.engfailanal.2013.04.011.

2. Jur, T. A.; Windham, R. L. 2009. Stress analysis and the cause of the fracture of a Clevis at the end of a hydraulic piston rod, Journal of Failure Analysis and Prevention 9: 558-562. 
http://dx.doi.org/10.1007/s11668-009-9290-6.

3. Fuštar, B.; Lukačević, I.; Dujmović, D. 2018. Review of fatigue assessment methods for welded steel structures, Advances in Civil Engineering 2018: 1-16. https://doi.org/10.1155/2018/3597356.

4. Henk den Besten. 2018. Fatigue damage criteria classification, modelling developments and trends for welded joints in marine structures, Ships and Offshore Structures 13 (8): 787-808. https://doi.org/10.1080/17445302.2018.1463609.

5. Hobbacher, A. F. 2016. Recommendations for Fatigue Design of Welded Joints and Components, 2nd edition. Springer International Publishing. XVI, $143 \mathrm{p}$. https://doi.org/10.1007/978-3-319-23757-2.

6. Chattopadhyay, A.; Glinka, G.; El-Zein, M.; Qian, J.; Formas, R. 2011. Stress analysis and fatigue of welded structures, Welding in the World 55: 2-21. https://doi.org/10.1007/BF03321303.

7. Rother, K.; Rudolph, J. 2011. Fatigue assessment of welded structures: practical aspects for stress analysis and fatigue assessment, Fatigue and Fracture of Engineering Materials and Structures 34 (3): 177-204. https://doi.org/10.1111/j.1460-2695.2010.01506.x.

8. Sonsino, C. M. 2009. A consideration of allowable equivalent stresses for fatigue design of welded joints according to the notch stress concept with the reference radii $r_{\text {ref }}=1.00$ and $0.05 \mathrm{~mm}$. Welding in the World 53 No 3/4: R64-R75. https://doi.org/10.1007/BF03266705.

9. Taras, A.; Unterweger, H. 2017. Numerical methods for the fatigue assessment of welded joints: influence of misalignment and geometric weld imperfections, Engineering Structures and Technologies 9(1): 9-24. https://doi.org/10.3846/2029882X.2017.1299968.

E. Narvydas, R. Dundulis, N. Puodziuniene

\section{ROD END STRESS ANALYSIS FOR HYDRAULIC CYLINDER OF LIVE FLOOR CONVEYING SYSTEM}

S u m m a r y

Rod end failures are rare but still happening in the rod eyes of hydraulic cylinders. Stress analysis at the location of failure is very important for design improvement and identification the causes of failure. Performed finite element stress analysis shoved a preference of equivalent stress located at $1 \mathrm{~mm}$ distance from the weld toe comparing to the maximal stresses calculated at the root of $1 \mathrm{~mm}$ radius artificial fillet. Mounting of the hydraulic cylinder that creates a possible misalignment between the resultant reaction force and the rod, will create a stress increase in the external ring of the rod eye at the location of the observed failure.

Keywords: rod end failure, welded joint, hydraulic cylinder.

Received November 20, 2019 Accepted April 15, 2020 